\title{
LA TEORÍA DE LOS SISTEMAS Y LA HISTORIA DE LA LITERATURA
}

\section{Manuel Maldonado Alemán}

Universidad de Sevilla

\section{SOBRE LA FUNDAMENTACIÓN TEÓRICA DE LA HISTORIA DE LA LITERATURA}

1.1. Desde diversas perspectivas se viene insistiendo en las últimas décadas que toda forma de conocimiento humano, también el científico, y, por supuesto, el histórico-literario, está determinado por teorías. Se afirma, en este sentido, que el conocimiento y la observación no parten de la percepción pura y simple, pues ésta nunca es inmediata, sino más bien de un punto de vista concreto, de un problema previo que se pretende resolver, de una teoría subyacente que dirige la observación. Siempre será lo teórico, y no la percepción sensitiva, lo primordial en todo proceso cognitivo, sin que se dé la posibilidad de una observación, descripción o explicación pura o neutra. Con la ayuda de teorías implícitas o explícitas, que pueden tener el carácter de conceptos, esquemas, marcos referenciales, modelos, sistemas, etc., el ser 
humano observa, describe o explica el mundo que le rodea, sistematizando y estructurando sus experiencias.

Esta primacía de lo teórico tiene validez incluso en doble sentido: las teorías no son sólo constitutivas del conocimiento, sino también del ámbito de experiencia al que se refiere ese conocimiento. Por un lado, determinan el modo específico de experimentar los fenómenos y, por otro, delimitan los fenómenos que van a ser objeto de conocimiento, es decir, seleccionan de todos los hechos potencialmente observables aquellos que son relevantes en relación con la cuestión teórica planteada. De ello se deduce que las teorías no encuentran su aplicación primera en el proceso de investigación o explicación de un determinado fenómeno, sino más bien en el proceso de su constitución: el dominio de investigación tiene que ser primeramente construido a la luz de una teoría, para poder ser posteriormente investigado o explicado también con la ayuda de teorías. Describir y explicar un determinado fenómeno significa, por tanto, insertarlo en una teoría en cuyo marco cobra sentido (Maldonado Alemán, 1997a; 1998).

Al igual que en otras disciplinas, esta primacía de lo teórico es de especial relevancia en los estudios histórico-literarios, pues del fundamento teórico elegido dependerán la determinación de su objeto y función, la elección de los problemas y datos específicos, y la formulación de las hipótesis. Particularmente, de ese fundamento dependerá cómo se resuelvan dos de los problemas fundamentales de la historiografía literaria: uno referente a las cuestiones de principio que pretenden dar respuesta a los interrogantes de qué es literatura y cómo se relacionan la literatura y la sociedad - una relación que explicaría el cambio literario-; y otro de método que consiste en responder a la cuestión de cómo seleccionar, clasificar, valorar e interpretar los datos pertenecientes al ámbito literario (Tacca, 1985: 196 y ss.). A este respecto, desde el trasfondo teórico de la teoría de los sistemas y a partir de una crítica a la propuesta recepcional de H. R. Jauß, trataremos de responder en este trabajo, en primer lugar, a las cuestiones de principio, para a continuación determinar el objeto y función que, desde ese horizonte, corresponden a los estudios histórico-literarios. Propondremos la necesidad de que la teoría de los sistemas, en la versión desarrollada por N. Luhmann, sea complementada con un modelo evolucionista del cambio literario.

1.2. En la discusión en torno a la fundamentación teórica de la historia de la literatura que se ha llevado a cabo en los últimos treinta años, que en lo esencial es un fiel reflejo del desarrollo teórico y meto- 
dológico de la propia teoría y crítica literarias, ha tenido una importancia decisiva, especialmente en Alemania, el escrito de H. R. Jauß La historia literaria como desafío a la ciencia literaria. Con esta obra se inicia un importantísimo cambio de rumbo en la historiografía literaria. Su punto de partida lo constituye una crítica al inmanentismo sustancialista, a la consideración del discurso literario como una realidad autónoma, portadora de sentido único e invariable, que, al conceptuar la obra como sustancia, desestima la mutabilidad del significado artístico y la historicidad del juicio crítico (Jauß, 1967: 171-172). La historia de las múltiples recepciones a las que una misma obra ha sido sometida evidencia, por el contrario, que existen tantas experiencias estéticas en la recepción de un texto como grupos distintos de receptores hay de ese mismo texto. Debido a la inexistencia de univocidad en la actividad lectora, la historia de la literatura, lejos de contemplarse como una simple yuxtaposición cronológica de autores y obras, debe considerar tanto la naturaleza histórica del mensaje literario como la relatividad de la perspectiva que lo juzga, para de este modo configurarse en torno a una relación dialógica entre obra y público que dé cuenta del proceso dinámico de producción y recepción, y supere efectivamente el abismo existente entre Historia y Literatura. En consecuencia, la historia de la literatura debe concebirse desde la perspectiva de la recepción y del efecto producido por la obra, esto es, a modo de una historia de la recepción literaria que se fundamente en la reconstrucción de los diversos horizontes de expectativas cambiantes en los que ha tenido lugar la lectura de las obras en el pasado. Esta reconstrucción permitirá aclarar, en el marco del continuo diálogo entre obra y público, a qué preguntas respondió el texto en otro tiempo; es decir, dilucidará cómo el lector de antaño pudo entender la obra, lo que posibilitaría apreciar la diferencia hermenéutica entre la comprensión de antes y la de ahora (Jauß, 1967: 177-189). La historia de las múltiples recepciones distintas de una obra evitará, así, plantear la pregunta por el sentido del texto, para centrar el interés en la cuestión de por qué un texto tiene un determinado sentido para un grupo concreto de lectores (Acosta, 1989). Sólo de esta forma se logrará establecer una relación efectiva entre Historia y Literatura, y se comprobará la condición ciertamente histórica de los fenómenos literarios. Esta renovación de la historia literaria requiere, empero, según Jauß, la superación del objetivismo causal proveniente de la tradición positivista del siglo XIX, así como el abandono del realismo mimético que establece una relación determinista entre las estructuras socioeconómicas y los fenómenos artísticos. 
Mientras que Jauß se limitó, en lo esencial, a fundamentar teóricamente, en el sentido expuesto, la investigación histórica de la recepción literaria, otros investigadores han llevado a la práctica sus planteamientos (Grimm, 1977; Weber, 1978; Flynn/Schweickart, 1986; Segers (ed.) 1993). Poco a poco estos estudios han ido mostrando las dificultades y limitaciones que presenta la propuesta recepcional de Jauß. Esos problemas se derivan del concepto de horizonte de expectativas y de la dificultad que entraña su comprobación empírica y reconstrucción histórica. Pero ante todo se ha constatado que restringir la función de la historia literaria a la descripción de las reacciones recepcionales de los lectores no puede más que derivar en una reconstrucción parcial y fragmentaria del pasado histórico-literario (Grimm, 1977: 80). Por tal motivo, a partir de la segunda mitad de la década de los setenta, numerosos historiadores de la literatura toman conciencia de la necesidad de recurrir a una nueva fundamentación teórica de los estudios histórico-literarios que supere la concepción reduccionista de la estética de la recepción y contemple de forma integradora todos los procesos y fenómenos que efectivamente intervienen en la comunicación literaria. Esta nueva orientación, que pretende valorar el desarrollo histórico de la literatura desde el contexto comunicativo en el que se produce, se ha visto fortalecida en los últimos años con la aplicación a los estudios literarios de la denominada teoría de los sistemas ${ }^{1}$.

\section{LA PERSPECTIVA SISTÉMICA EN LOS ESTUDIOS LITERARIOS}

2.1. La perspectiva sistémica supone una orientación decididamente pragmática de la investigación literaria. El nuevo enfoque propone sustituir el textocentrismo (Iglesias Santos, 1994: 312; Rusch, 1994) propio de la visión estructuralista por la noción de sistema y contempla la literatura de manera funcional y dinámica como un modo de interacción social y de comunicación, como un fenómeno complejo que, al estar integrado en una amplia red de acciones sociales, deja de ser valorado exclusivamente a partir de la inmanencia textual. La lite-

1 Sobre la aplicación de la teoría de los sistemas a la literatura, vid. en especial los trabajos publicados en Even-Zohar (1990); Schmidt (ed.) (1993); Berg/Prangel (eds.) (1993; 1995; 1997). 
ratura se conceptúa ahora, en lo fundamental, como un sistema de acciones, procesos y fenómenos literarios, en el que sus distintos componentes se integran y vinculan recíprocamente. El concepto de sistema se refiere, a un tiempo, siguiendo a A. Angyal, uno de los clásicos del pensamiento sistémico, tanto a la totalidad como a la forma específica de organización de los elementos que lo componen. Esas entidades no se constituyen en componentes del sistema en virtud de sus propiedades inmanentes, sino gracias a la posición que ocupan y función que desempeñan en la totalidad organizada del sistema. Es, por tanto, la función operativa de la entidad la que determina su pertenencia al sistema (Angyal, 1941: 20) ${ }^{2}$.

Entre las orientaciones sistémicas más relevantes, que desde hace algunos años vienen elaborándose casi simultáneamente en diferentes países, destacan las siguientes:

- La Teoría Empírica de la Literatura (Empirische Theorie der Literatur), concebida y desarrollada por el grupo de investigación NIKOL. Desde 1984 este grupo está integrado en el Instituto LUMIS (Institut für Empirische Literatur-und Medienforschung) de la Universidad alemana de Siegen. A él pertenecen, principalmente, A. Barsch, P. Hejl, D. Meutsch, G. Rusch, S. J. Schmidt - su director- y R. Viehoff. Esta orientación se fundamenta en la teoría de los sistemas de $\mathrm{N}$. Luhmann y sostiene un concepto constructivista de sistema.

- La Teoría de los Polisistemas (Polysystems Theory), desarrollada en la Universidad de Tel Aviv especialmente por I. EvenZohar, Z. Shavit, G. Toury y S. Yahalom, a partir del funcionalismo dinámico del Formalismo ruso y de la teoría social de la literatura y del arte de P. Bourdieus.

- La Teoría Estructural-Funcional de la Literatura (StrukturalFunktionale Theorie der Literatur), elaborada en la Universidad de Múnich por el grupo de investigación Sozialgeschichte der deutschen Literatur 1700-1900, siguiendo la teoría de los sistemas de T. Parsons y la concepción sociológica de la cultura de W. L. Bühls. A esta orientación pertenecen F. Meyer y C.-M. Ort.

2 Vid. a este respecto también Bertallanffy (1972). 
- La Teoría Sistémica de la Literatura (Systemtheorie der Literatur), desarrollada por D. Schwanitz, N. Werber, G. Plumpe y H. de Berg sobre la base de la teoría de los sistemas de N. Luhmann.

- Y, por último, la orientación representada por los grupos canadienses HOLIC (Toward a History of the Literary Institution in Canada), perteneciente al Research Institute for Comparative Literature de la Universidad de Alberta en Edmonton y formado por E. D. Blodgett, M. V. Dimic, A. G. Purdy y S. Tötösy; y CRELIQ, integrado en el Centre de Recherche en Littérature Québécoise de la Universidad de Laval en Quebec, entre cuyos miembros figuran M. Lemire, J. Melançon, C. Moisan y D. Saint-Jacques.

Los modelos sistémicos asumidos por estas orientaciones constituyen, en términos generales, un fundamento teórico válido para la observación, descripción, organización y explicación, tanto sincrónica como diacrónica, de las actividades, fenómenos y procesos que intervienen en la comunicación literaria. En especial, la concepción de los sistemas sociales desarrollada por N. Luhmann -que él mismo valora como cambio de paradigma en la teoría de los sistemas (1984: 15 y ss.) y a la que nos circunscribiremos en este trabajo-, por cuanto se asienta en principios funcionales (diferenciación, autorreferencia, autonomía, etc.) y no en simples postulados clasificatorios, ofrece un modelo explicativo de índole integradora, funcional y dinámica de la organización, desarrollo e interdependencia de los fenómenos sociales, que tiene significativas implicaciones para la conceptuación del arte y la literatura, y de su historia ${ }^{3}$.

2.2. Incorporando la teoría de la autopoiesis de $\mathrm{H}$. R. Maturana y F. J. Varela a sus reflexiones (Maldonado Alemán, 1997a), Luhmann concibe los sistemas como entidades autorreferentes y autopoiéticas, que tienen la capacidad de establecer relaciones consigo mismo y de diferenciar esas relaciones de las que establecen con su medio (1984: 31; Schwanitz, 1990b: 107). En general, Luhmann distingue tres tipos fundamentales de sistemas: los sistemas vivos, psíquicos y sociales. Estos sistemas se diferencian entre sí merced a un modo propio de

3 Sobre la teoría de los sistemas de Luhmann, vid. Haferkamp/Schmid (eds.) (1987); Kiss (1990); Gripp-Hagelstange (1995). 
operar autopoiético. De este modo, las operaciones vitales son características de los sistemas vivos, la conciencia es el modo de operar de los sistemas psíquicos y la comunicación es la actividad que distingue a los sistemas sociales. Estos sistemas son autorreferentes puesto que contienen en sí mismos la diferencia con su entorno, y son autopoiéticos por cuanto es el sistema el que crea y elabora, desde sí mismo, su propia estructura y los elementos que lo componen. En este sentido, los sistemas sólo pueden constituirse y conservarse como tales gracias a la elaboración y mantenimiento de una diferencia directriz (Leitdifferenz) con su entorno, una diferencia que está incluida en el concepto mismo de sistema (Luhmann, 1984: 57). Es precisamente la diferencia con su entorno lo que define al sistema y la que, en definitiva, le otorga identidad; pues los sistemas no sólo se orientan ocasionalmente o por adaptación hacia su entorno, sino de manera estructural, y no podrían existir sin él. En ese caso, la descripción y explicación que se realice de un sistema implica necesariamente la aclaración de su diferencia con el entorno, desde la que aquél cobra sentido. La noción de diferencia, en consecuencia, constituye el concepto fundamental de la teoría de los sistemas desarrollada por Luhmann (1984: 35; Schwanitz, 1990a: 51), hasta el extremo de que algunos investigadores consideran este modelo sistémico como una teoría de la diferencia (Plumpe/Werber, 1993: 11).

Para poder mantener y regular esa diferencia, cada sistema debe elaborar unos límites que lo separen del entorno. Los límites han de distinguir claramente lo que es elemento del sistema de lo que pertenece al entorno mismo, pero igualmente deben posibilitar la apertura y la relación del sistema con el exterior. Esos límites permitirán seleccionar lo que se incluye en el sistema y rechazar lo que no se considera parte del mismo ${ }^{4}$. Los límites tienen, por consiguiente, la doble función de separar y unir al sistema con su entorno: cuando los límites están bien definidos, los elementos o bien pertenecen al sistema o bien al entorno; y precisamente gracias a esa diferenciación puede relacionarse el sistema con su entorno. Por otro lado, lo que forma el entorno sólo puede ser determinado desde el propio sistema, desde su especificidad operacional y organizativa. Pues, a diferencia de la unidad sistémica, el entorno carece de límites, es un horizonte abierto. Aunque el entorno propiamente no es un sistema, sí coinciden en él numerosos sistemas, lo que obliga a distinguir, igualmente, entre el entorno de un

${ }^{4}$ Precisamente la existencia de esos límites sistémicos y su correspondiente función distinguen el concepto de sistema del concepto de estructura. 
sistema y los sistemas en el entorno; o sea, a diferenciar las relaciones de dependencia entre entorno y sistema, de las relaciones de dependencia entre sistemas. Y, ciertamente, la diferenciación sistémica lleva a que la distinción fundamental entre sistema y entorno se repita en la propia unidad sistémica, lo que explica la aparición de múltiples sistemas funcionalmente diferenciados. Cada uno de los sistemas así surgidos no mantiene, en rigor, una relación de diferencia respecto de otros sistemas, sino sólo con su entorno, el cual incluye, como ya hemos indicado, aparte de lo que el sistema en cuestión rechaza, todos los demás sistemas. Para un sistema determinado, las demás unidades, también las no sociales, formarán parte de su entorno. De aquí se deduce que cada subsistema social tendrá, en el ámbito general del sistema comunicativo de la sociedad, un entorno social externo, compuesto por los sistemas vivos y psíquicos, y otro interno, integrado por el resto de subsistemas sociales (Plumpe/Werber, 1993: 21). Estas consideraciones sobre sistema y entorno hacen necesaria la formulación explícita de una teoría de la diferenciación sistémica, que aquí expondremos brevemente sólo en relación con los sistemas sociales.

Según Luhmann, a diferencia de los sistemas vivos y psíquicos, tan sólo en los sistemas sociales puede darse el fenómeno de la comunicación, por lo que ésta se constituye en su eje central: la sociedad es, en lo esencial, un sistema de comunicación, y la interacción comunicativa es el proceso que produce los componentes del sistema social; del mismo modo que los sistemas sociales se reproducen gracias a que la comunicación origina de modo autorreferente comunicación. Esa actividad comunicativa que caracteriza y define a un sistema social es, ante todo, elección entre un conjunto de posibilidades. La comunicación consiste, concretamente, en la fusión en un todo único de una triple selección: selección dentro de un horizonte de referencias de la información que va a ser actualizada en el acto comunicativo; selección de una acción comunicativa en la que se concrete y comunique la información anteriormente conformada; y, por último, selección de un acto de comprensión tras la aprehensión, por parte de un receptor, de la acción comunicativa anterior. La comunicación resultaría, finalmente, de la síntesis que la capacidad diferenciadora del entendimiento establece entre la información, la acción comunicativa y la comprensión seleccionadas (Luhmann, 1984: 194 y ss.; Prangel, 1993: $16-17)^{5}$.

5 Luhmann rechaza, a este respecto, por representacional, el modelo matemático o clásico de la comunicación de Shannon y Weaver que concibe el proceso comunicativo, 
En los sistemas sociales, el establecimiento de la diferencia directriz entre sistema y entorno se efectúa operativamente mediante la comunicación así estructurada y gracias a un código binario que la fundamenta y regula de un modo específico. Merced a la generalización simbólica relativa a conceptos como verdad, dinero, belleza o justicia, y mediante la esquematización binaria con arreglo a un código como verdadero/falso, tener/no tener, bello/feo o justo/injusto, surgidos en el transcurso de la evolución social (Plumpe/Werber, 1993: 16), se han ido desarrollando en el seno del sistema global de la sociedad múltiples subsistemas diferenciados y funcionalmente independientes que la componen internamente, tales como el económico, político, jurídico, científico, educativo, religioso, artístico, etc., cada uno de ellos autorreferente y autopoiético, con un ámbito propio de comunicación y de actuación, que limita su entorno. Estos sistemas se diferencian funcionalmente unos de otros gracias al código específico que regula la comunicación que los define. Ese código establece las oposiciones binarias que el sistema elige para diferenciarse de su entorno y que servirán de fundamento para su organización estructural. Así, por ejemplo, el sistema jurídico utiliza el código justo/injusto, el económico tener/no tener, el artístico la oposición bello/feo, la ciencia verdadero/falso. Sobre la base de esas oposiciones binarias específicas de cada sistema, que constituyen su diferencia directriz, la unidad sistémica selecciona y elabora las informaciones procedentes del entorno y regula internamente su comunicación. En el desarrollo histórico de los sistemas esas abstracciones binarias se han concretado, ciertamente, de múltiples maneras; pero siempre han permanecido vinculadas a la sempiterna diferencia directriz subyacente. Lo que el sistema acepta y excluye como componente del sistema, lo que reconoce como arte, economía o ciencia, sus actividades de observación y descripción de la realidad, se ajustan estrictamente al código elegido, a su diferenciación específica (Luhmann, 1981: 246). De este modo, por poner un ejemplo, la ciencia estructura en su interior la interacción comunicativa exclusivamente de acuerdo con el código verdadero/falso, y no en consideración a la oposición binaria justo/injusto o bello/feo; y, consiguientemente, admite en su seno lo que considera verdadero y rechaza lo establecido como falso. Cualquier otro aspecto, perspectiva $o$ código es para ese sistema irrelevante y lo ignora. Lo que no significa que no exista otro sistema que se ocupe de ello: la sección de la reali-

básicamente, como un acto de transmisión o transporte de información entre dos interlocutores. Para una crítica de ese modelo, vid. Maldonado Alemán (1994; 1997a). 
dad que no tiene cabida en un sistema, bien puede tenerla en otro; incluso lo que un sistema ha aceptado como dominio propio podrá ser observado y explicado de manera distinta por otro sistema desde la singular perspectiva que imponga su código. $\mathrm{Y}$, en efecto, desde un punto de vista funcional, los sistemas se constituyen para dar solución, de un modo muy particular, a determinados problemas y necesidades; un hecho que otorga cohesión al propio sistema y que impide la equivalencia funcional entre sistemas. En consecuencia, el sistema jurídico se limita exclusivamente a la regulación de conflictos; el económico, a la administración y distribución de los bienes; etc. Y ningún otro sistema codifica o elabora la información como lo hace el sistema jurídico, o como lo realiza el sistema económico. Por consiguiente, la jurisprudencia no puede ser sustituida por la economía, ni el arte por la religión. No puede existir redundancia funcional: cualquier interferencia de un sistema en otro significaría un conflicto consigo mismo que le impediría actuar correctamente y podría llevarlo a su destrucción. En este sentido se puede afirmar que la especificidad de cada uno de los sistemas sociales modernos se fundamenta en su diferenciación funcional (Schwanitz, 1990a: 51), en las peculiares funciones que en particular les corresponden. Gracias a su autonomía y especificidad funcional, los sistemas operan de modo cerrado. Y, precisamente por esa razón, aunque los diferentes sistemas pueden, en efecto, observarse y describirse mutuamente, son incapaces de comunicarse entre sí: al intentarlo, cada uno de ellos regulará sus propias acciones comunicativas según el código que los define, sin que en ningún momento puedan asumir el de otras unidades sistémicas. La comunicación es siempre intrasistémica, nunca intersistémica; es descripción, desde un código exclusivo, de los acontecimientos que acaecen tanto en el propio sistema como en el ajeno.

Tanto es así, que, para Luhmann, la sociedad moderna se compone tan sólo de comunicaciones y de funciones comunicativas y no de seres humanos. El ser humano, que constituye en sí mismo un sistema psíquico que tiene en la conciencia y en el lenguaje su propio modo de operación autopoiética, forma parte del entorno de los sistemas sociales sin ser componente de los mismos (Luhmann, 1984: 191 y ss.). O sea, aunque ciertamente los seres humanos son imprescindibles para la constitución de un sistema social, no son, en cambio, condición suficiente: indispensable será que entre ellos se produzca una interacción comunicativa de la que resulte la asunción de una función determinada, para que de su especificidad emerja un sistema social. Y ello es así porque los individuos no participan en un sistema social en cuanto 
tales sujetos, sino sólo en orden a la función específica que desempeñan en él. No es su posición social o características individuales lo que define al miembro del sistema, sino la función que asuma. De este modo, un mismo individuo puede ser parte constitutiva de diferentes sistemas sociales - por ejemplo, como abogado, profesor, católico, miembro de un partido político o de una sociedad deportiva-, sin que en ellos tenga que actuar de la misma manera. En cada uno de los sistemas sociales a los que pertenece, el sujeto se comportará de acuerdo con el modelo de realidad, convenciones, código, valores y normas de conducta vigentes en el sistema en cuestión (Barsch, 1993b: 41). Y su actuación en un sistema determinado no deberá tener consecuencias directas para la que realice en otro sistema: un buen profesor no tendrá que ser necesariamente un buen católico, como un buen católico no tendrá que ser obligatoriamente un buen abogado. Pues, dentro del sistema, por las razones expuestas, los miembros interactúan de un modo operacionalmente cerrado, gracias a lo cual son capaces de diferenciar las interacciones que son características del sistema de las que no lo son.

En resumen, merced al código binario que los caracteriza, el sistema global de la sociedad constituye un conjunto de sistemas - que en realidad son subsistemas del sistema social general- diferenciados y funcionalmente independientes. Cada sistema forma una unidad autónoma, autorreferencial y operacionalmente cerrada, o sea, autopoiética, con un dominio particular de investigación y con formas propias de comunicación, observación y explicación.

2.3. Siguiendo este enfoque sistémico, se puede afirmar que lo que en realidad distingue a la literatura no puede ser simplemente el conjunto de obras y autores que la integran, en cuanto entidades autónomas e invariables, sino ante todo las acciones comunicativas que en ella se realizan, o sea, el complejo formado por actante-texto-contexto, y la forma de organización de esas acciones, esto es, su configuración como sistema social. Si bien es cierto que el texto forma el eje de los procesos de comunicación literaria, toda vez que los sujetos de esa comunicación - autor, receptor, intérprete, etc.- se constituyen en cuanto tales gracias al propio texto, la literatura presenta una configuración mucho más compleja que la simple suma de obras y autores. En lo esencial, la literatura compone un conjunto estructurado de acciones comunicativas de naturaleza sociocultural, interrelacionadas e interdependientes; o sea, la literatura se estructura como un sistema social de comunicación, autorregulado y autoorganizado, compuesto por la vin- 
culación recíproca de acciones comunicativas que se articulan como procesos y que dan lugar a fenómenos literarios específicos. Esas actividades, fenómenos y procesos son múltiples y evidencian una naturaleza muy diversa y compleja. Abarcan desde las acciones concretas que realizan en el proceso de comunicación literaria los autores, receptores, editores, libreros, medios de comunicación de masas, intérpretes, críticos, instituciones educativas, traductores, etc., hasta manifestaciones y fenómenos comunicativos como los de interferencia literaria y cultural, interpretaciones normativas, procesos de institucionalización y canonización, normas estéticas, mercado literario, intertextualidad cultural, interdependencia mediática, adaptaciones cinematográficas, etc. (Rusch, 1991: 316 y ss.; 1993: 170 y ss.). De acuerdo con ello, la comunicación literaria que se produce en el seno del sistema de la literatura se concibe como un conjunto de acciones comunicativas sociales, realizadas intencionalmente bajo determinadas presuposiciones (convenciones, normas, valores, etc.) en una situación específica con la ayuda de un medio de comunicación y conforme a una estrategia concreta.

En cuanto sistema social complejo, el sistema de la literatura presenta una organización interna y una diferenciación externa frente a otros sistemas, y cumple además una función que no es asumida por ningún otro sistema social. El sistema literario se estructura internamente en cuatro tipos elementales de acciones según las funciones que asuman los participantes comunicativos: producción, transmisión, recepción y elaboración (en forma de comentarios, críticas, interpretaciones, traducciones, etc.) de los textos considerados literarios (Schmidt, 1980: 62 y ss., y cap. 5) ${ }^{6}$. Se constata que las acciones literarias comprobables empíricamente corresponden a uno o a una combinación de varios de estos dominios parciales de la comunicación literaria, los cuales se derivan de una estabilización específica de las relaciones surgidas entre los elementos del proceso comunicativo. De la interrelación y acoplamiento de esos cuatro tipos básicos de acciones resultan los procesos de comunicación literaria, cuya totalidad constituye el sistema de la literatura de una sociedad dada en un momento determinado.

Como factor aglutinante y fundamento común a las distintas acciones e interacciones que se producen en un mismo sistema literario, presente o pasado, actúa el concepto de literatura que han desarrollado

6 Para una precisión de estas acciones literarias, vid. Barsch (1993a). 
los diferentes participantes en el sistema, un concepto que regula la actuación literaria dentro del sistema y que designa las convenciones, normas, ideas, etc. que aquéllos establecen y aceptan respecto de la naturaleza, significado y función de la literatura, y en lo concerniente a su relación con la sociedad (Barsch, 1991: 103). Todo concepto de literatura es, así, elemento constitutivo, imprescindible y determinante de un sistema literario, e interviene por esa razón como criterio de delimitación de ese sistema frente a otros sistemas literarios. En consecuencia, la especificación de los límites de un sistema literario ha de ir íntimamente vinculada a la aclaración del concepto de literatura que a él subyace. De aquí se deduce la posibilidad de que en un mismo grupo social coexistan diferentes conceptos de literatura y, por consiguiente, distintos sistemas literarios. En ese caso, esos sistemas literarios constituirían subsistemas del sistema general de la literatura de esa sociedad.

El sistema social de la literatura se diferencia externamente de otros sistemas sociales merced a la vigencia de normas y convenciones que regulan específicamente la actuación comunicativa en el sistema. Para cualquier sistema literario moderno ${ }^{7}$, S. J. Schmidt (1980: 89, 92, 106 y ss., 159 y 174) establece, hipotéticamente, dos convenciones básicas que regulan la comunicación literaria: la convención estética y la convención de polivalencia. Estas dos convenciones, o mejor, macroconvenciones, actúan como criterios generales de delimitación de las acciones comunicativas literarias de otras formas de comunicación no literarias, propias de otros sistemas sociales.

La convención estética, cuya función consiste en especificar el modo de la comunicación literaria (Schmidt, 1980: 100), implica que quien quiera participar en dicha comunicación debe estar dispuesto a admitir y orientarse hacia normas, valores y reglas de significación distintos de los establecidos por las reglas de verdad o de utilidad práctica que son propias del modelo de realidad de su mundo de experiencia social, y que rigen la comunicación no literaria. Es decir, los participantes comunicativos no pueden implantar, como es el caso en la comunicación no literaria, el modelo de realidad vigente en la sociedad como marco referencial de comprobación semántica del contenido de verdad de sus afirmaciones o acciones comunicativas literarias; antes al contrario, estas acciones, que en la mayoría de los casos son

7 Según Schmidt (1989), los orígenes del sistema literario moderno se remontan en el caso concreto de Alemania a la segunda mitad del siglo XVIII. 
contrafácticas y poseen una diferencia reconocible respecto de la realidad de experiencia habitual en la vida cotidiana, deben ser juzgadas, primariamente, de acuerdo con las categorías de valoración y reglas de significación que los participantes en la comunicación literaria consideran, explícita o implícitamente, como estéticamente relevantes en ese momento de acuerdo con la poética vigente. Por consiguiente, los textos que son considerados literarios no deben ser juzgados, primariamente, según los criterios verdaderolfalso, útil/inútil o viable/no viable, válidos para la realidad extraliteraria que configura el entorno del sistema literario, sino particularmente según las categorías estéticoliterarias que correspondan en cada momento histórico al concepto de literatura imperante.

El segundo criterio de delimitación, la convención de polivalencia, establece que los participantes realicen la comunicación estética realmente de modo polivalente, evitando la univocidad propia de la comunicación no literaria, la cual se rige por la convención de monovalencia. A diferencia de lo que ocurre en la realidad extraliteraria, los participantes comunicativos están legitimados a actuar con relación a un mismo texto que consideran literario de manera variada y diversa, siguiendo criterios de optimación, en consonancia con sus necesidades, capacidades, intenciones y motivaciones subjetivas. De esta manera, la polivalencia debe ser pretendida, normalmente, por el autor de textos literarios y esperada por el receptor de esos textos. Por esa razón el presupuesto de la polivalencia implica un factor de libertad semántica, o sea, un marco de fantasía y de creatividad individual, en virtud del cual los autores pueden producir textos a los que distintos receptores en un mismo momento, o bien un único receptor en contextos temporales y situacionales diferentes, pueden asignar legítimamente resultados de recepción satisfactorios y divergentes entre sí, parcial o totalmente (Hauptmeier/Schmidt, 1985: 18). La vigencia de la convención de polivalencia implica, en consecuencia, la asunción tácita por parte de los sujetos comunicativos de la condición plural, abierta, relativa y cambiable de las actividades de recepción e interpretación literarias ${ }^{8}$.

8 Dado el carácter hipotético de ambas convenciones, en los últimos años vienen realizándose numerosas investigaciones a fin de obtener su justificación empírica. Si en lo concerniente a la función que desempeña la convención estética en la comunicación literaria actual se han obtenido notables resultados, no así, en cambio, en lo que respecta a la influencia efectiva y específica de la convención de polivalencia en el proceso de producción y recepción de textos. Vid. a este respecto Ibsch (1988); Kramaschki (1991); Groeben/Schreier (1992). 
Por otro lado, en el sistema social general, al sistema de la literatura le corresponden funciones específicas de índole cognitiva, normativa y emotiva que no son cumplidas por ningún otro subsistema social (Schmidt, 1980: 121-123; Hauptmeier/Schmidt, 1985: 84; Schmidt, 1987: 66-67). La función cognitiva atañe a la posibilidad de que los participantes comunicativos, mediante la comparación del modelo de realidad posible o imaginable, surgido de la comunicación literaria, con su propio modelo de realidad social, puedan conocer más exactamente, confirmar o modificar en determinados aspectos su ámbito cognitivo y su actuación tanto social como individual. De esta manera, el sistema de la literatura se configura como el escenario elegido por una sociedad dada para confirmar, criticar, rechazar o presentar alternativas al modelo de realidad imperante en esa misma sociedad. Debido a que en la comunicación literaria se tematizan públicamente conflictos normativos individuales, la confrontación que se produce entre los participantes comunicativos y las concretizaciones textuales puede llevar, igualmente, a que aquéllos consoliden, cuestionen, modifiquen o eliminen de sus sistemas de presuposiciones las normas y los juicios de valor que rigen su propia actuación. En este sentido, la comunicación literaria ejerce también una función normativa. Por último, la función emocional se refiere a la satisfacción de las necesidades individuales de placer hedonista que la literatura puede provocar de manera diversa en los autores y receptores, y a la ampliación de los márgenes de sus posibilidades emocionales.

En conclusión, la perspectiva sistémica, en la visión de la Teoría Empírica de la Literatura que hemos elegido aquí ${ }^{9}$, trata de establecer unos criterios de delimitación de las acciones comunicativas literarias, evitando ofrecer una definición esencialista de la literariedad de los textos, por cuanto considera que los textos no son literarios en sí mismos, o sea que lo estético-literario no es una cualidad intrínseca del texto, sino que es, más bien, una función que determinados productos verbales cumplen en un momento y en un lugar concreto. En el ámbito de la comunicación literaria, los textos son producidos, leídos, interpretados, comentados, traducidos o vendidos como literarios, y su validez literaria se circunscribe exclusivamente a ese ámbito comunicativo y al contexto situativo y temporal en el que se produce la comunicación. O sea, la literariedad de una obra dependerá sólo de la posibili-

9 Para una crítica y precisión de la Teoría Empírica de la Literatura, vid. Werber (1992); Vliet/Velden (1993); Kramaschki (1993); Barsch (1993b); Groeben (1994); Jäger (1994); Ort (1995). 
dad de que las cualidades que se le atribuyan sean declaradas literarias en orden a las normas y a los criterios estéticos imperantes en el sistema literario vigente. En consecuencia, la integración de una acción o fenómeno comunicativo, en principio no literario, en un sistema literario determinado supondrá que se le apliquen a esa acción o fenómeno las normas y convenciones propias del sistema, y que, en ese caso, sea juzgado de acuerdo con el código literario/no literario. De este modo, idénticos textos, acciones, fenómenos o procesos comunicativos pueden pasar de ser valorados como literarios a no serlo, y viceversa, en dependencia del sistema en el que se integren. Además, cada época o sistema podrá concretar o actualizar de una manera propia el código binario general literario/no literario, en el que se fundamenta la diferencia directriz del sistema con su entorno, y determinar, según sus propias normas y criterios, lo que es o no es literariamente válido. Qué normas específicas son consideradas relevantes en cada momento dependerá de la correspondiente concepción estético-literaria subyacente de la que en definitiva se derivan, que al igual que las propias normas en modo alguno posee una validez absoluta o ahistórica. Criterios como los de originalidad y creatividad, que en el sistema literario moderno acrecientan el valor estético de una obra, lo disminuían en otras épocas. $Y$ textos que en determinados momentos han cumplido una función religiosa, filosófica o jurídica, hoy son considerados, por el contrario, como literarios. Las normas, concepciones y criterios estético-literarios, la propia función de los textos, así como la concreción del código literario/no literario son variables históricas, es decir, se manifiestan como una dimensión sociocultural cambiante en el tiempo y en el espacio, y pueden abarcar, como vuelve a mostrar la historia de la literatura, desde la belleza, harmonía, ficción, originalidad o innovación hasta una valoración especial del cómo de la organización textual.

\section{EL CAMBIO LITERARIO}

3.1. La condición de las actividades, fenómenos y procesos que integran el sistema literario y su propia organización estructural muestran que la naturaleza de la literatura es eminentemente social, institucional, funcional y dinámica. El sistema literario, pese a ser un sistema autónomo, no es en modo alguno un sistema autárquico: al estar inte- 
grados en una sociedad determinada, sus elementos evolucionan y cambian con esa misma sociedad, aunque no necesariamente de manera mecánica ni sincrónica, ni tampoco determinista; ni siquiera de forma unidireccional, dado que la influencia puede ser recíproca. Los componentes sistémicos se interrelacionan internamente y, a su vez, establecen relaciones externas con otros sistemas e instituciones sociales. Y de la concurrencia convergente de ese conglomerado de relaciones tanto intrasistémicas como extrasistémicas resulta el cambio literario.

3.2. En la historiografía de la literatura, C. Martindale (1990) diferencia cuatro modelos básicos acerca del cambio literario: la concepción denominada de la «gran tradición», la del reflejo, la inmanente y la evolucionista. La primera de ellas asevera que en la historia de las artes no se produce ningún cambio sistemático o progreso auténtico; la «gran tradición», a cuya conformación contribuyen individualmente los distintos autores e instituciones literarias, es una constante histórica. Para Martindale, esta visión constituye una simplificación artificial que contradice los hechos empíricamente constatables; es una «noexplicación» del desarrollo histórico (1990: 22) que ignora cambios tan importantes como, por ejemplo, que la epopeya, en cuanto género, se circunscribe a las culturas prerrenacentistas y desaparece en las sociedades modernas. En rigor, esta perspectiva se muestra incapaz de aclarar, ya que incurriría en una contradictio in adiecto, el surgimiento de la propia tradición en la que fundamenta su propuesta.

A diferencia de este primer enfoque, en los estudios histórico-literarios ha gozado de una gran estimación el modelo extrínseco que, fundamentado en la teoría del reflejo, considera la literatura como un sistema cultural, influenciado y propulsado directamente por el conjunto de factores que componen su entorno social: concepciones políticas y filosóficas, valores éticos y religiosos, estructuras económicas, normas sociales y progreso tecnológico. La historia literaria es, desde esta perspectiva, un reflejo de la historia social, y su desarrollo y evolución encuentran explicación primera en la propia transformación de las estructuras y fenómenos sociales. La plasmación conceptual la recibe este modelo de teorías miméticas de corte platónico o aristotélico, y, ante todo, de teorías hegelianas, marxistas o neomarxistas acerca de la historia y la evolución literaria. Todas ellas niegan que el desarrollo histórico-literario obedezca a causas internas al sistema literario, por lo que rechazan la condición autónoma de la literatura. Se constata, sin embargo, que no siempre es suficiente ni necesario apelar a factores 
externos para explicar el cambio literario. Quizás por ello, estas propuestas se muestran incapaces de justificar adecuadamente la relación determinista que ellas mismas establecen entre estructuras sociales y fenómenos artísticos; e incluso de responder de manera congruente a la cuestión de por qué, como aseveran, el arte ha de ser y es reflejo e imagen mimética de esas mismas estructuras.

Por el contrario, la perspectiva intrínseca se fundamenta en la consideración de que la evolución y transformación de la literatura se producen de acuerdo con sus propios principios constitutivos. Y es precisamente esa autonomía inherente al sistema literario lo que justifica y da sentido a su existencia. Esta perspectiva asume un modelo cíclico de cambio literario (Sztompka, 1993; Peer, 1995: 105 y 108) que, por cuanto compara los fenómenos históricos con el desarrollo orgánico de los seres vivos, entiende que, al igual que éstos, la historia literaria progresa en fases sucesivas - nacimiento, crecimiento, florecimiento, decadencia y muerte- que comparten entre sí características y propiedades substanciales. El enfoque intrínseco presenta, sin embargo, el inconveniente de que sólo aclara y especifica en parte los mecanismos y factores que motivan el cambio literario, precisamente por restringir la perspectiva a los elementos internos al sistema.

La concepción evolucionista del cambio literario, por el contrario, evita, a nuestro entender, las carencias y problemas que presentan tanto la visión extrínseca como la intrínseca. Esta perspectiva, siguiendo la concepción biológica de la evolución en cuanto teoría de la selección, que es considerada como la formulación primera de una teoría universal ${ }^{10}$ de los sistemas de índole histórica (Eibl, 1996: 13; Fleischer, 1989: 34 y ss.), concibe la historia literaria como un proceso darwinista, constituido por etapas de adaptación, variación y selección. Los mecanismos de adaptación obedecen a los principios básicos de mutación y selección ${ }^{11}$. La selección nunca es resultado exclusivo de las variaciones internas del sistema, sino consecuencia de la interac-

10 Hoy en día, numerosos investigadores conciben que la teoría de la evolución, aunque fue descubierta en la biología, describe un mecanismo de cambio y transformación de aplicación universal. De acuerdo con esta interpretación, todo lo existente, desde la materia hasta las mismas ideas, puede ser explicado como resultado de un proceso previo de selección y adaptación. Sobre los orígenes y desarrollo de la teoría de la evolución, vid. Fleischer (1989: 15-81); sobre su justificación científica, vid. Weiner (1994).

11 En este sentido, más que a un simple proceso de cambio o transformación, la evolución se refiere sólo a aquel cambio que se produce siguiendo los principios de mutación y selección. 
ción con su entorno, o sea, de la transformación del sistema de la sociedad en su conjunto. En los procesos evolutivos es, así, decisiva la interacción del sistema con su medio; una interrelación en la que el sistema es la instancia que propone y el medio, la que selecciona. La selección sólo se produce, en ese caso, en el marco de las variantes facilitadas por el sistema y está limitada por las propiedades y particularidades que éste presenta, de manera que, de no existir una propuesta adecuada, surge un conflicto y peligra la adaptación. La selección, por consiguiente, provoca el cambio del sistema mediante la eliminación de lo que es impropio o inadecuado al entorno del sistema, y la aceptación de lo apropiado. En ese proceso, invariablemente, los sistemas actúan en su entorno a fin de solucionar determinados problemas y, gracias a la existencia de esos problemas, se vinculan y adaptan a su entorno. Y siempre será el entorno el que decida qué propuesta de solución será la adecuada. Se da, por ende, una vinculación procesual y funcional entre los fenómenos literarios y los fenómenos sociales, que configura un cúmulo de interdependencias recíprocas en el que cada elemento condiciona y es condicionado a su vez por otros elementos. Todo cambio literario es, así, en definitiva, resultado de un proceso previo de selección y corroboración, originado no de manera excluyente por factores externos, o bien factores internos, sino gracias a una interacción de ambos.

Una de las constantes, en este caso interna, que regularmente motivan el cambio literario es la necesidad de innovación con la que los escritores intentan incrementar el potencial artístico de sus creaciones, a fin de atraer la atención y conseguir la aceptación de los receptores. Es un hecho comúnmente aceptado que la repetición prolongada de un mismo estímulo provoca en el observador, en virtud de la costumbre que ello impone, automatismo y desinterés. El uso reiterado de un mismo contenido, recurso o artificio, implica en literatura la pérdida creciente de su efecto estético y potencial innovador, lo que obliga a la desautomatización ${ }^{12}$ mediante la renovación continua y novedosa (Martindale, 1994: 197; Fokkema, 1994: 152). A la postre, una de las funciones primordiales de la literatura, que impele al cambio, consiste en la introducción de novedades.

3.3. Entendemos que, por su capacidad descriptiva y explicativa, y por evitar el reduccionismo propio de otros enfoques, el modelo evo-

12 Vid. a este respecto las propuestas realizadas en el seno del Formalismo ruso, en especial las de V. Sklovskij (1916). 
lucionista es una propuesta teórica válida para la aclaración del cambio literario. Además, presenta la significativa ventaja, como explicaremos a continuación, de permitir su aplicación sistémica. No obstante, la compatibilidad de la concepción evolucionista de la historia con la teoría de los sistemas de N. Luhmann presenta algunas dificultades, derivadas de los conceptos estáticos de autorreferencia, autopoiesis y autonomía, en los que el sociólogo alemán fundamenta su enfoque sistémico.

Para Luhmann, como hemos señalado anteriormente, todo sistema social, también el literario, es un sistema autopoiético, es decir, un sistema autónomo y operacionalmente cerrado ${ }^{13}$, organizado de manera autoproductora, autorreguladora y autorreferencial. La condición autopoiética del sistema no significa, en modo alguno, que la unidad opere de forma aislada o autárquica. La autorreferencialidad, autorregulación y autoproducción del sistema no implican su aislamiento y desvinculación absoluta del entorno, o sea, un proceder circular. Considerando este aspecto, Luhmann (1992: 163-166; 1995: 16-19 y 30-33) ha introducido recientemente en su teoría el concepto de acoplamiento estructural, tomado de H. R. Maturana y F. J. Varela (1990). Este concepto, que precisa la influencia del entorno sobre el sistema, es complementario al de autopoiesis e indica la relación de dependencia, adecuación y compatibilidad que se establece entre la unidad sistémica y su entorno. El acoplamiento estructural es resultado de la interacción recurrente entre sistema y entorno, y más concretamente de la interacción entre sistema y sistemas en el entorno, que de este modo se involucran recíprocamente en la realización de sus respectivas autopoiesis. Todas las operaciones del sistema están subordinadas al mantenimiento y mejoramiento en ese entorno de la autopoiesis, que es, en definitiva, la que garantiza su existencia. Por consiguiente, todo cambio estructural de un sistema estará acotado por el mantenimiento de la organización autopoiética; y las interacciones tratarán de desencadenar cambios compatibles con dicha conservación. Ante las variaciones ambientales, la coherencia interna del sistema compensa sus perturbaciones estructurales y vuelve a establecer la compatibilidad con el nuevo estado del entorno. En este sentido, los sistemas son estructuralmente plásticos, merced a lo cual son capaces de compen-

13 En general, la teoría de los sistemas diferencia tres tipos de sistemas: sistemas abiertos que intercambian con su entorno energía e información; sistemas cerrados que sólo pueden intercambiar energía con el entorno; y, por último, sistemas aislados que no realizan ningún tipo de intercambio con su entorno (Jantsch, 1982: 56 y ss.; 1989). 
sar irregularidades y alteraciones causadas por influencias externas. Ello significa, por ende, que los sistemas autopoiéticos son, en cuanto a su organización, sistemas homeostáticos, aptos para adaptarse al medio en el que interactúan. Si las interacciones con el entorno son destructivas, y el sistema es incapaz de asimilarlas y adaptarse a ellas, éste interrumpirá su autopoiesis y perderá su adaptación, es decir, no logrará mantener su existencia y desaparecerá (Maturana/Varela, 1990: 84 y ss.). En definitiva, ante las perturbaciones del entorno, el sistema sólo tiene dos posibilidades: adaptarse o desaparecer. Y esto le ocurre no sólo a los organismos vivos, en los que Maturana y Varela centran sus investigaciones, sino también a los sistemas psíquicos y sociales.

Pese a la introducción del concepto de acoplamiento estructural, perfectamente compatible con la visión evolucionista del cambio, la teoría de los sistemas de Luhmann sigue considerando a los sistemas sociales, en lo esencial, en orden a su condición estática y valora, en consecuencia, el acoplamiento estructural de esos sistemas como estado y no como proceso. Con ello, este modelo sistémico no aprecia de manera suficiente la dinámica evolutiva de los sistemas sociales y necesita, para su aplicación a la historia literaria, de una revisión parcial. Esa modificación ha de posibilitar que la atención primaria se desplace de la situación estática, perdurable y continuada, surgida tras el acoplamiento estructural, al proceso continuo de acoplamiento evolutivo y dinámico, a la serie de fases sucesivas de mutaciones y selecciones por las que transcurre ese acoplamiento; por lo que, finalmente, deberán contemplarse asimismo, y con la misma intensidad y atención, los periodos 'catastróficos' (Eibl, 1996: 23) en cuyo transcurso un sistema determinado sucumbe. $Y$ es a este respecto que la aplicación e integración de la concepción evolucionista en la teoría de los sistemas de Luhmann puede ser extraordinariamente útil a la historiografía literaria.

Desde esta perspectiva integradora, la selección constituye el modus operandi del funcionamiento dinámico del sistema literario, y su transformación y cambio obedecen a sus regularidades y particularidades. El desarrollo histórico de la literatura, y de las artes en general, se configura, en ese caso, no como proceso inmanente, sino como evolución de unos sistemas que reiteradamente tratan de adaptarse a su entorno mediante operaciones de variación y selección, y que, al mismo tiempo, en virtud de la prioridad concedida a la necesidad de innovación, están obligados a la renovación desautomatizadora. En ese proceso evolutivo, cuando en los mecanismos de selección es dominante la 
referencia externa del entorno, tiende a aparecer una literatura de tipo realista; cuando domina, en cambio, la referencia interna del sistema, el tipo de literatura es esteticista. Entre ambos extremos, se desarrolla la historia literaria, ante todo en la época moderna (Plumpe, 1985: 256). La visión evolucionista y sistémica de la historia supera, así, una historia literaria concebida como una mera yuxtaposición descriptiva de hechos, en la que el desarrollo histórico configura un continuo homogéneo, uniforme y acumulativo, donde cada etapa recibe la misma categoría sin distinción de grado, valor o importancia. El enfoque que proponemos refuta esta visión cuantitativa del desarrollo histórico y, al diferenciar con claridad los periodos de continuidad sincrónica de aquellos de transformación diacrónica, resalta con determinación los procesos históricos de cambio cualitativo.

3.4. Dada la complejidad de los procesos evolutivos, en el transcurso de la historia literaria es conveniente diferenciar entre variación en el sistema y transformación del sistema (Titzmann, 1991: 428). La variación intrasistémica es ciertamente innovadora, pero transcurre dentro de las normas y regularidades constitutivas del sistema literario, las cuales no vulnera. En la transformación, sin embargo, la intensidad de la innovación altera sustancialmente los principios reguladores del sistema, prescinde de ellos parcial o totalmente y se produce un auténtico cambio literario ${ }^{14}$. El cambio literario resulta, así, de la transformación de las normas, principios, criterios y valores constitutivos de un sistema literario. En dependencia de la intensidad con la que se produzca y de la cantidad e importancia de las normas y regularidades a las que afecte, esa transformación puede provocar un cambio inmanente del sistema, que conduce a una nueva situación sistémica, o un cambio trascendente, que, proyectándose al exterior, traspasa los límites del sistema y origina un sistema nuevo y completamente diferente. La nueva situación sistémica será regulada por las normas y convenciones que han permanecido inalteradas; el nuevo sistema, en cambio, estará sustentado por un nuevo concepto de literatura, lo que implica el abandono del anterior. Asimismo, en ese proceso el cambio literario puede suponer tanto un cambio de estructuras como un cambio de funciones. Es decir, al producirse el cambio, las estructuras pueden permanecer invariables pero asumir nuevas funcio-

14 Sobre la aplicación de esta diferenciación al estudio del cambio literario acaecido en la obra de un mismo autor, vid. Maldonado Alemán (1996); para el fenómeno de la interferencia literaria, vid. Maldonado Alemán (1997b). Vid. también los trabajos publicados en Titzmann (ed.) (1991). 
nes, como también pueden aparecer nuevas estructuras que desempeñan funciones ya existentes; $y$, por supuesto, estructuras y funciones pueden cambiar simultáneamente (Titzmann, 1991: 429).

\section{OBJETO Y FUNCIÓN DE LA HISTORIA LITERARIA}

4.1. Esta consideración de la literatura como sistema social de comunicación que evoluciona y se transforma tiene importantes implicaciones tanto para la determinación del objeto de estudio de la historia literaria como para la dilucidación de su función. Pues si la literatura, al articularse como sistema de comunicación, deja de concebirse como un corpus más o menos amplio de obras literarias canonizadas, el dominio de investigación de los estudios histórico-literarios ya no podrá reducirse al análisis o interpretación del texto literario, como así ha sido tradicionalmente, sino que, por el contrario, tendrá que ampliarse a todo el conjunto del sistema de la literatura. El objeto de estudio estará constituido, entonces, por todas aquellas acciones de naturaleza social que han hecho posible la producción, la transmisión, la recepción y la elaboración de los textos considerados literarios, así como por las manifestaciones y fenómenos que resultan de esas acciones y procesos. Para una historia de la literatura, ello establece la necesidad de considerar las relaciones internas de las actividades y fenómenos literarios de los distintos subsistemas que en cada momento histórico pueden distinguirse en el sistema literario de una sociedad determinada; además de las relaciones externas de ese sistema literario con otros sistemas sociales, e incluso literarios y no literarios de otros países (Segers, 1994: 162; Moisan, 1987: 77 y 196). En ese caso, la investigación histórico-literaria deberá prestar atención a la organización y función de los múltiples sistemas y subsistemas literarios que pueden diferenciarse en el desarrollo histórico de una sociedad, y a su transformación en el tiempo; y la historia de la literatura de esa sociedad será la historia de esos mismos sistemas literarios.

En esos procesos de investigación, el texto literario desempeñará, en consecuencia, una función ciertamente necesaria pero no exclusiva: una función necesaria por cuanto el ámbito de estudio de la historia literaria está formado por todas las acciones comunicativas que se efectúan con relación al texto; y una función no exclusiva porque el texto sólo es objeto de investigación a condición de que aparezca en la 
constelación de los procesos sociales de comunicación literaria como un texto producido, transmitido, recibido o elaborado, esto es, si la unidad textual se ha constituido en objeto de una acción literaria. Por consiguiente, el texto, en cuanto entidad autónoma, deja de ocupar la atención preferente de la actividad investigadora, y sólo las acciones que se realicen con él constituyen el objeto prioritario de estudio. Cuestiones acerca del significado textual, sobre la producción, recepción o interpretación de un texto no pueden ser solucionadas recurriendo directamente a la estructura textual, sino ante todo examinando su relación con el sujeto productor, receptor o intérprete.

La función de la historia literaria consistirá, entonces, en describir y explicar, de forma integradora y considerando todas las relaciones de interdependencia, la organización, evolución y funcionamiento real de la literatura en la sociedad, en contextos culturales precisos, con todos sus elementos, actividades y procesos, en términos de relaciones y no de esencias, y alejándose de una concepción idealista e intemporal del arte verbal. En lugar de centrar la atención en la interpretación de las obras literarias, se describen y explican las condiciones de producción, mediación, recepción, elaboración e institucionalización de los fenómenos literarios, así como la red de relaciones que se establece entre esos factores y procesos, y con el entorno social; lo que obliga a incorporar al estudio de las actividades y fenómenos literarios el amplio sistema de presuposiciones e interrelaciones contextuales, en cuyo marco esas manifestaciones literarias cobran sentido y evolucionan, o sea, sus circunstancias económicas, sociales, políticas, culturales, etc. Ello supone, además del análisis y estudio de su contexto sociohistórico y cultural, atender a la observación, descripción y explicación, tanto en un eje diacrónico como sincrónico, de la estructura, función y dinámica de las acciones comunicativas, fenómenos y procesos que han hecho y hacen posible la aparición, articulación y transformación del sistema global de la literatura y de sus correspondientes subsistemas, considerando expresamente las características de su desarrollo evolutivo y la naturaleza específica del resultado alcanzado. $Y$ ese estudio ha de realizarse, precisamente por tratarse de un enfoque sistémico, integrando y conectando todos los componentes, vínculos e influencias del sistema, y estableciendo las regularidades que explican su organización y transformación ${ }^{15}$.

15 Sobre la necesidad de establecer las regularidades y leyes que rigen el desarrollo histórico de la literatura, vid. Titzmann (1991: 416 y ss.); Peer (1994: 179 y ss.); Martindale (1990; 1994: 192 y ss.). 
En definitiva, la historia de la literatura, concebida como historia de sistemas literarios, ha de considerar las relaciones intrasistémicas, o sea, estructurales e internas de cada sistema, establecidas entre las distintas actividades, procesos y fenómenos que lo componen; las relaciones extrasistémicas, es decir, las relaciones y factores externos que condicionan la estructura y evolución del propio sistema; y, por último, las relaciones intersistémicas que permitan analizar, por ejemplo, la evolución de los géneros, motivos, temas, recursos, estilos, funciones y convenciones estéticas, las relaciones entre conceptos de literatura diferentes, el fenómeno de la interferencia literaria, las relaciones entre obras pertenecientes a distintos sistemas, la evolución de un autor y su obra, el cambio en el gusto estético de los receptores, la interdependencia entre concepto de literatura, convenciones literarias y organización sistémica, etc.

\section{Referencias bibliográficas}

Acosta, L. A. (1989). El lector y la obra. Teoría de la recepción literaria. Madrid: Gredos.

ANGYAL, A. (1941). «A Logic of Systems». En Systems Thinking, F. E. Emery (ed.), 17-29. Harmondsworth, 1969.

BARSCH, A. (1991). "Populäre Literatur" als Forschungsproblem einer empirischen Literaturwissenschaft». Wirkendes Wort 1, 101-119.

- (1993a). «Handlungsebenen, Differenzierung und Einheit des Literatursystems». En S. J. Schmidt (ed.), 144-169.

- (1993b). «Kommunikation mit und über Literatur: $\mathrm{Zu}$ Strukturierungsfragen des Literatursystems». SPIEL (Siegener Periodicum zur Internationalen Empirischen Literaturwissenschaft) 12/1, 34-61.

BARSCH, A./ RuSCH, G./VIEHOFF, R. (eds.) (1994). Empirische Literaturwissenschaft in der Diskussion. Fráncfort del Meno: Suhrkamp.

Berg, H. DE/ PRANGel, M. (eds.) (1993). Kommunikation und Differenz. Systemtheoretische Ansätze in der Literatur- und Kunstwissenschaft. Opladen: Westdeutscher Verlag.

- (1995). Differenzen. Systemtheorie zwischen Dekonstruktion und Konstruktivismus. Tubinga: Francke.

- (1997). Systemtheorie und Hermeneutik. Basilea: Francke.

BERTALLANFFY, L. VON (1972). «Vorläufer und Begründer der Systemtheorie». En Systemtheorie, L. von Bertallanffy, 17-28. Berlín: Colloquium.

EIBL, K. (1996). «Literaturgeschichte, Ideengeschichte, Gesellschaftsgeschichte-und "Das Warum der Entwicklung"». Internationales Archiv für Sozialgeschichte der deutschen Literatur 21/2, 1-26. 
Even-Zohar, I. (1990). Polysystem Studies. Volumen monográfico de Poetics Today 11/1.

FleISCHER, M. (1989). Die Evolution der Literatur und Kultur. Grundsatzfragen zum Entwicklungsproblem (ein systemtheoretisches Modell). Bochum: Studienverlag Dr. Norbert Brockmeyer.

FLYNN, E. A./ SCHWEICKART, P. P. (eds.) (1986). Gender and Reading. Essays on Readers, Text and Contexts. Baltimore/ Londres: Johns Hopkins University Press.

FoKKEMA, D. (1994). «Empirie und Geschichte». En A. Barsch/ G. Rusch/ R. Viehoff (eds.), 142-156.

GRIMM, G. (1977). Rezeptionsgeschichte. Grundlegung einer Theorie. Mit Analysen und Bibliographie. Múnich: Fink.

GRIPP-HAGELSTANGE, H. (1995). Niklas Luhmann. Eine erkenntnistheoretische Einführung. Múnich: Fink.

Groeben, N. (1994). «Der Paradigma-Anspruch der Empirischen Literaturwissenschaft». En A. Barsch/ G. Rusch/R. Viehoff (eds.), 21-38.

Groeben, N./ SchreIER, M. (1992). «The Hypothesis of the Polyvalence Convention: A Systematic Survey of the Research Development from a Historical Perspective». Poetics 21, 5-32.

HAFERKAMP, H./ SCHMID, M. (eds.) (1987). Sinn, Kommunikation und soziale Differenzierung. Beiträge zu Luhmanns Theorie sozialer Systeme. Fráncfort del Meno: Suhrkamp.

HAUPTMEIER, H./ SCHMIDT, S. J. (1985). Einführung in die Empirische Literaturwissenschaft. Braunschweig/ Wiesbaden: Vieweg.

IBSCH, E. (1988). «Zur literarischen Sozialisation. Beobachtungen zur Polyvalenz-Konvention». En SPIEL (Siegener Periodicum zur Internationalen Empirischen Literaturwissenschaft) 7/2, 333-345.

IgLESIAS SANTOS, M. (1994). «El sistema literario: teoría empírica y teoría de los polisistemas». En Avances en Teoría de la Literatura, D. Villanueva (comp.), 309-356. Santiago de Compostela: Universidad.

JÄGER, G. (1994). «Systemtheorie und Literatur. Teil I. Der Systembegriff der Empirischen Literaturwissenschaft». Internationales Archiv für Sozialgeschichte der deutschen Literatur 19/1, 95-125.

JANTSCH, E. (1982). Die Selbstorganisation des Universums. Vom Urknall zum menschlichen Geist. Múnich: dtv.

- (1989). «System, Systemtheorie». En Handlexikon der Wissenschaftstheorie, H. Seiffert/ G. Radnitzky (eds.), 329-338. Múnich: Philosophia Verlag.

JAUB, H. R. (1967). Literaturgeschichte als Provokation der Literaturwissenschaft. En Literaturgeschichte als Provokation, H. R. Jauß, 144-207. Fráncfort del Meno: Suhrkamp, 1970.

Kiss, G. (1990). Grundzüge und Entwicklung der Luhmannschen Systemtheorie. Stuttgart: Enke.

KramasCHKI, L. (1991). «Anmerkungen zur Ästhetik- und Polyvalenzkonvention der Empirischen Theorie der Literatur. Ein Beitrag zur Kon- 
ventionalismus-Debatte in der Literaturwissenschaft». SPIEL (Siegener Periodicum zur Internationalen Empirischen Literaturwissenschaft) 10/2, 207-233.

- (1993). «Zur Integration von Systemkonzepten in eine Empirische Literaturwissenschaft als kritische Sozialwissenschaft». En S. J. Schmidt (ed.), 101-143.

Luhmann, N. (1981). Ist Kunst codierbar?. En Soziologische Aufklärung, N. Luhmann, vol. 3, 245-266. Opladen: Westdeutscher Verlag.

- (1984). Soziale Systeme. Grundriß einer allgemeinen Theorie. Fráncfort del Meno: Suhrkamp, $4^{\mathrm{a}}$ ed., 1991.

- (1992). Die Wissenschaft der Gesellschaft. Fráncfort del Meno: Suhrkamp.

- (1995). Soziologische Aufklärung 6. Die Soziologie und der Mensch. Opladen: Westdeutscher Verlag.

Maldonado AlemÁn, M. (1994). Construcción y literatura. Elementos para una fundamentación teórico-científica de la investigación literaria. Universidad de Sevilla. Tesis Doctoral.

- (1996). «Innovación y cambio literario en Nebeneinander de Georg Kaiser». Revista de Filología Alemana 4, 135-155.

- (1997a). «El constructivismo radical y la investigación literaria». Revista de Filología Alemana 5, 31-64.

- (1997b). «La poesía pura de Stéphane Mallarmé y la poesía absoluta de Paul Celan. Una aproximación a un caso de interferencia literaria desde la perspectiva sistémica». Fòrum 10.

- (1998). «Sobre la fundamentación metateórica de la investigación literaria». Philologia Hispalensis 13.

Martindale, C. (1990). The Clockwork Muse. The Predictability of Artistic Change. Nueva York: Basic Books.

- (1994). «Die Fakten der Literaturgeschichte. Oder: Was in der Literaturgeschichte wirklich passiert». En A. Barsch/ G. Rusch/ R. Viehoff (eds.), 190-201.

MATURANA, H. R./ VARELA, F. J. (1990). El árbol del conocimiento. Las bases biológicas del conocimiento humano. Madrid: Debate.

MoISAN, C. (1987). Qu' est-ce que l'histoire littéraire. París: PUF.

ORT, C.-M. (1995). «Systemtheorie und Literatur. Teil II. Der literarische Text in der Systemtheorie». Internationales Archiv für Sozialgeschichte der deutschen Literatur 20/1, 161-178.

PeER, W. VAN (1994). «Das erste und das zweite Gesetz der Literaturgeschichte». En A. Barsch/ G. Rusch/ R. Viehoff (eds.), 176-189.

- (1995). «Die Vergangenheit vorhersagen: Einige Modelle der Literaturgeschichtsschreibung». En S. J. Schmidt (ed.), 98-115.

PlumPE, G. (1985). «Systemtheorie und Literaturgeschichte. Mit Anmerkungen zum deutschen Realismus im 19. Jahrhundert». En Epochenschwellen und Epochenstrukturen, H. U. Gumbrecht/ U. Link-Heer (eds.), 251-264. Fráncfort del Meno: Suhrkamp. 
Plumpe, G./ Werber, N. (1993). «Literatur ist codierbar. Aspekte einer systemtheoretischen Literaturwissenschaft». En S. J. Schmidt (ed.), 9-43.

PRANGEL, M. (1993). «Zwischen Dekonstruktionismus und Konstruktivismus. $\mathrm{Zu}$ einem systemtheoretisch fundierten Ansatz von Textverstehen». En H. de Berg/ M. Prangel (eds.), 9-31.

RusCH, G. (1991). «Zur Systemtheorie und Phänomenologie von Literatur. Eine holistische Perspektive». SPIEL (Siegener Periodicum zur Internationalen Empirischen Literaturwissenschaft) 10/2, 305-339.

- (1993). «Literatur in der Gesellschaft». En S. J. Schmidt (ed.), 170193.

- (1994). Systemtheorien in der Germanistischen Literaturgeschichtsschreibung. LUMIS-Schriften 38: Universität-Gesamthochschule Siegen.

SCHMIDT, S. J. (1980). Grundriß der Empirischen Literaturwissenschaft, vol.

I: Der gesellschaftliche Handlungsbereich Literatur. Braunschweig/ Wiesbaden: Vieweg.

- (1987). «Der Radikale Konstruktivismus: Ein neues Paradigma im interdisziplinären Diskurs». En Der Diskurs des Radikalen Konstruktivismus, S. J. Schmidt (ed.), 11-88. Fráncfort del Meno: Suhrkamp.

- (1989). Die Selbstorganisation des Sozialsystems Literatur im 18. Jahrhundert. Fráncfort del Meno: Suhrkamp.

- (1993). «Kommunikationskonzepte für eine systemorientierte Literaturwissenschaft». En S. J. Schmidt (ed.), 241-268.

- (ed.) (1993). Literaturwissenschaft und Systemtheorie. Positionen, Kontroversen, Perspektiven. Opladen: Westdeutscher Verlag.

- (ed.) (1995). Empirische Literatur- und Medienforschung. LUMISSchriften Sonderreihe, vol. VII: Universität-Gesamthochschule Siegen.

SCHWANITZ, D. (1990a). Systemtheorie und Literatur. Ein neues Paradigma. Opladen: Westdeutscher Verlag.

- (1990b). «Selbstreferenzielle Systeme». Zeitschrift für Literaturwissenschaft und Linguistik ( $\mathrm{LiLi}$ ) 77, 100-125.

- (1993). «Systemtheoretischer Handlungsbegriff und literarische Kommunikation». SPIEL (Siegener Periodicum zur Internationalen Empirischen Literaturwissenschaft) 12/1, 72-80.

SEgERS, R. T. (1994). «Durchbruch und Kanonisierung: Eine neue Provokation für die Literaturgeschichtsschreibung?». En A. Barsch/ G. Rusch/ R. Viehoff (eds.), 157-175.

- (ed.) (1993). Etudes des réception/ Reception studies. Proceedings of the xith Congress of the International Comparative Literature Association, vol. 8. Berna: Peter Lang.

Skıovsku, V. (1916). «Kunst als Kunstgriff». En Theorie der Prosa, V. Sklovskij, 7-24. Fráncfort del Meno: Fischer, 1984.

SZTOMPKA, P. (1993). The Sociology of Social Change. Oxford: Blackwell.

TACCA, O. (1985). «Historia de la literatura». En Métodos de estudios de la obra literaria, J. M. Díez Borque (coord.), 187-228. Madrid: Taurus, 1989. 
TrTZMANN, M. (1991). «Skizze einer integrativen Literaturgeschichte und ihres Ortes in einer Systematik der Literaturwissenschaft». En M. Titzmann (ed.), 395-438.

- (ed.) (1991). Modelle des literarischen Strukturwandels. Tubinga: Niemeyer.

VLIET, H. VAN/ VELDEN, A. VAN DER (1993). «Zu einer radikal neuorientierten Empirischen Theorie der Literatur». SPIEL (Siegener Periodicum zur Internationalen Empirischen Literaturwissenschaft) 12/1, 23-33.

WEBER, H.-D. (ed.) (1978). Rezeptionsgeschichte oder Wirkungsästhetik. Konstanzer Diskussionsbeiträge zur Praxis der Literaturgeschichtsschreibung. Stuttgart: Klett-Cotta.

WEINER, J. (1994). The Beack of the Finch. A Story of Evolution in Our Time. Nueva York: Alfred A. Knopf.

WERBER, N. (1992). Literatur als System. Zur Ausdifferenzierung literarischer Kommunikation. Opladen: Westdeutscher Verlag. 